Fall 2006

\title{
Science education on the U.S./Mexico border: Field-based studies for future teachers in bilingual/binational schools
}

\author{
William H. Robertson \\ University of Texas at El Paso \\ Judith $\mathrm{H}$. Munter \\ University of Texas at El Paso \\ Claudia Garcia \\ University of Texas at El Paso
}

Follow this and additional works at: https://digitalscholarship.unlv.edu/jpme

\author{
Repository Citation \\ Robertson, William H.; Munter, Judith H.; and Garcia, Claudia (2006) "Science education on the \\ U.S./Mexico border: Field-based studies for future teachers in bilingual/binational schools," Journal of \\ Praxis in Multicultural Education: Vol. 1: No. 1, Article 4. \\ DOI: 10.9741/2161-2978.1018 \\ Available at: https://digitalscholarship.unlv.edu/jpme/vol1/iss1/4
}

This Article is protected by copyright and/or related rights. It has been brought to you by Digital Scholarship@UNLV with permission from the rights-holder(s). You are free to use this Article in any way that is permitted by the copyright and related rights legislation that applies to your use. For other uses you need to obtain permission from the rights-holder(s) directly, unless additional rights are indicated by a Creative Commons license in the record and/ or on the work itself.

This Article has been accepted for inclusion in Journal of Praxis in Multicultural Education by an authorized administrator of Digital Scholarship@UNLV. For more information, please contact digitalscholarship@unlv.edu. 


\title{
Science Education on the U.S./Mexico Border: Field-Based Studies for Future Teachers in Bilingual/Binational Schools
}

\section{William H. Robertson, Judith Munter, and Claudia Garcia}

\begin{abstract}
The University of Texas at El Paso's field-based program of studies for future teachers provides opportunities for powerful learning through a dialectical union of reflection and action. Methods courses in academic disciplines are linked with seminars and coursework on community partnerships, dual language education and culturally responsive education. This article illustrates the processes of planning, implementation and evaluation of this approach, highlighting the impacts of forging connections among schools, communities and university personnel to improve education on the U.S./Mexico border and in communities with culturally/linguistically diverse student populations. Parents, students and future teachers interact in bilingual workshops that center on pupil achievement and conceptually correct science education. Preliminary outcomes indicate that two-way dual language (TWDL) bilingual programs (i.e., validating native language literacy along with English language acquisition) with a strong parental engagement component provide a strong framework for teaching/learning that can help improve educational outcomes for ELL/immigrant children and deepen future teachers' skills and knowledge. Focusing on academic enrichment for all students, these field-based experiences enable future teachers to learn strategies that integrate students' and families' linguistic and cultural experiences as a resource for learning. The co-authors highlight qualitative data findings from the Science in Our Homes Ciencia en Nuestras Casas field-based project in a multilingual, multicultural K-8 school on the U.S./Mexico border, providing insights for educators in diverse communities whose efforts focus on closing the achievement gap for English language learners and/or immigrant students.
\end{abstract}

William H. Robertson is an Assistant Professor in the Teacher Education Department at the University of Texas at El Paso. His areas of expertise are science education, curriculum development and technology integration in K-16 classrooms. Judith H. Munter is Associate Dean and Associate Professor in the College of Education at UT El Paso. Her research interests include bilingual education, program evaluation, action research and service-learning in teacher education. Claudia Garcia is a graduate student with a bachelor's degree in biology and a minor in secondary education. As a future science instructor she is interested in researching teaching methods that aid ESL students. 
The United States is entering the new millennium much the way it began the twentieth century: with a substantial level of immigration that is hastening population growth and reshaping the ethnic composition of communities and schools throughout the nation. The recent 'great wave' of U.S. immigration began in the late 1960s and continues into the 21st century. By 2000, immigrants represented one in nine of all U.S. residents; their children represented one in five of all children under age 18. Children of immigrants represented an even higher share-one in four-of all school-age children who were low-income, defined by eligibility for the National School Lunch Program. The share of the overall K-12 population represented by children of immigrants is projected to expand, driven primarily by increases in the second generation. If current trends continue, children of immigrants will constitute 25 percent of the nation's school population by 2010 (Capps et al., 2005).

\section{Demographics and Diversity in the Borderlands}

In coming to this country and adjusting to American schools, immigrant students and their families travel long distances in physical, emotional and psychological terms. What has become increasingly clear in recent years, furthermore, is that recently arrived immigrants from non English-speaking countries encounter serious problems within the U.S. educational system. The dilemma facing schools and teachers serving these children is a difficult one. There is much ambiguity in educational circles and in the public mind about how students who are recent immigrants can best bridge the gap between cultures, with all that entails.

Over fifteen years ago, for example, Sosa (1990) reported alarming statistics about Hispanic student achievement, including a decline in high school completion rates, a steady rise in the dropout rate at younger ages and lower grade levels; and disproportionately high numbers of students two or more years behind grade level. In the first decade of the $21^{\text {st }}$ century, the goal of closing the achievement gap for Hispanic children continues to challenge the educational community (Fry, 2003); many schools continue to be linguistically segregated because of ongoing residential and school segregation by race, ethnicity, and income. The share of children with parents who are English language learners (ELLs) is also a matter of concern, since the language the parents speak may affect their involvement with the school. In 2000, six out of seven children designated as ELLs in Grades 1 to 5 lived in linguistically isolated households; in secondary school, two out of three did so. High levels of linguistic isolation point to the twin challenges of teaching ELLs and involving limited Englishspeaking families in their education. Over half (53 percent) of ELLs attend elementary and secondary schools where more than 30 percent of their classmates are also ELLs; conversely, 57 percent of English proficient students attend schools where less than 1 percent of all students are ELLs (Van Hook \& Fix, 2000).

Critical educators (e.g., Banks, 2005; Delgado-Gaitan, 2004; Nieto, 2002) have advanced a number of recommendations for schools and teachers to keep in mind when working with culturally/linguistically diverse students. 
Their research points to the need for stronger support between home-schoolcommunity networks. Parents should be encouraged to become actively engaged in the life of the school and in their children's education. A wide variety of options should be made available to accommodate diverse families' life styles, work hours, and weekly schedules (Mapp, 2002; Turner-Vorbeck, 2005). Rather than viewing culturally and linguistically diverse community members as indifferent to the plans and actions of school administrators, this approach to school improvement is based on understanding, appreciation and respect for the internal dynamics of diverse families and for the legitimacy of their values and beliefs.

A growing number of studies (e.g., Strand et al., 2003; Teitel, 2003) point to the benefits of preparing future teachers in field-based contexts, with courses that are collaboratively designed and managed. In the most effective programs, university faculty, public school personnel, and families all work together to design, implement, and evaluate educator preparation programs that aim to serve the needs of the diverse student population of the region. Community-based service learning programs that integrate field-based work in schools allow future teachers to more clearly understand the dynamics of teaching while developing effective partnerships with parents and community members who have direct connections to the school. Innovative partnerships integrated with coursework and field-based assignments help to strengthen the preparation of high quality new teachers and to enhance student learning opportunities. The following sections describe an innovative approach and an emerging academic model for integrating these elements of connected teaching and learning on the U.S./Mexico border.

\section{El Paso, Texas: Background and Context}

The City of El Paso, Texas is a bustling urban area of 600,000 people, more than $70 \%$ of whom are Mexican in origin. Across the river from El Paso sits the Mexican City of Juárez, a city of more than 1.2 million people; El Paso/Juárez represents the largest metropolitan area along the 2,000 mile U.S./Mexico border. Almost a quarter of El Paso's population is foreign born, and over 50 percent of El Paso's households speak Spanish as the language of preference (UTEP CIERP, 2005). More than $80 \%$ of UTEP's 19,000 students are MexicanAmerican and represent a promising pool of potential teachers, ready for opportunities to become highly qualified teachers and leaders for the next generation of children and youth, especially those from culturally and linguistically underrepresented populations. The College of Education graduates more than 500 teachers each year; many of these novice teachers are the first in their families to attend college.

\section{School-University Collaborations: UTEP's Field-Based Program of Studies}

For more than sixty years, educators have written about learning as a continuous, integrated process grounded in actual experience (e.g., Cross, 1994; Dewey, 1938; Hutchings \& Wutzdorff, 1988; Jacoby, 1994; Kuh, 1993; Liu, 
1995; Zlotkowski, 1996). That is, learners are not empty vessels waiting to be filled up with information and ideas. Rather, each learner enters educational settings with background knowledge about the topic at hand, mediated by her/his own life experiences and circumstances. Kolb (1984) described learning as "... a process whereby knowledge is created through the transformation of experience" (p. 38). Learning is seen as a process in which a person encounters new experiences, reflects on those experiences, develops new concepts, connects them with previous experiences, and ultimately, uses the concepts in subsequent actions as a guide for behavior. From these steps the person derives a new set of experiences and insights that lead to a repeat of the learning cycle.

At UTEP's College of Education, the preparation of future educators is collaboratively designed and managed, focused on authentic experiences in a field based setting. University faculty, public school personnel, and family/community members work together to design, implement, and evaluate educator preparation programs that aim to serve the needs of the diverse K-12 student population of the border region. UTEP students have been engaged in a number of field-based activities in partnership with local schools. One of these, 'Science in Our Homes/Ciencia en Nuestras Casas' created opportunities for future teachers from UTEP to become meaningfully involved in the culture of effective parent-school collaboration in a dual language (bilingual) teaching/learning context. UTEP students learn from practical, hands-on experiences while serving the community. Activities like family science nights further enable students to develop research processes and products to expand this important dimension of effective schools. These students are both active participants and reflective practitioners, empowering parents through educational activities in a dual language context, reflecting collectively on these experiences, and helping to rethink the nature of the relationship between the school and the community.

\section{Alicia Chacón International School: A Multilingual, Multicultural Context for Learning}

The Alicia Chacón International School is a K-8 dual language magnet school, located in the Ysleta Independent School District, El Paso, Texas. The Ysleta Independent School District (YISD) is one of the largest school districts in the region, providing instruction to over 46,300 school children, nearly $88 \%$ of whom are Hispanic. Approximately $73.4 \%$ of the total students are considered economically disadvantaged and $22.1 \%$ percent of the students in the YISD enter school as limited English proficient students. YISD schools provide valuable opportunities for future teachers/researchers to focus on unique bicultural encounters in border communities and schools. A growing number of schools in this district have implemented innovative pedagogical strategies in their respective campuses, developing alternative models of parent/community involvement that are culturally relevant, linguistically sound, and proven to create conditions for children's academic, social, and personal development (Lareau, 2000; Sheldon \& Epstein, 2004; Storch \& Whitehurst, 2001; Thomas \& Collier, 2002). These culturally responsive models differ sharply from 
traditional approaches that tend to minimize the role of native language and culture, beginning from deficit assumptions about immigrant families (Valencia, 1997).

The Alicia Chacón International School was founded in 1995 with students in grades K-2 and has expanded over the years, one grade level at a time. The school's two-way dual language (TWDL) program of studies provides instruction in all academic areas in English and Spanish for all children; additionally, the students select a third language (Russian, German, Japanese, or Chinese) for study from their time of entry. The overall student population is $95.7 \%$ Hispanic, and $71.8 \%$ receive free or reduced lunch. As an open enrollment institution, any El Paso area student may attend this K-8 school; like most magnet school programs, students are selected for enrollment by a lottery system.

The school's welcoming family-centered environment is an outstanding feature of the overall campus climate. Teachers and classrooms are organized as family groups, and the parents/community members are visibly integrated into every classroom. The Chacón model is grounded in the notion that parents are an integral component of school life, and that parental involvement can help the school culture develop and change, thus, improving opportunities for culturally diverse children. The success of this school's program is based upon the sense of shared mission and equal voice by all groups, and a strong sense of shared ownership and commitment.

\section{Two-Way Dual Language Education: An Essential Component of Culturally Responsive Instruction}

Calderón \& Minaya-Rowe's (2003) case study of the Alicia R. Chacón International School describes the school as a "multilingual magnet school that focuses on language and cultural development and that offers a rigorous curriculum based on interdisciplinary units and critical thinking skills" (p. 54). The school is one of a growing number of educational institutions recognizing the critical need for providing "specific and expanded literacy, linguistic, and academic skills so that all students can fully participate in a variety of educational, social, linguistic, cultural, and economic contexts" (Soltero, 2004, ix). Research and practice have clearly indicated the benefits of two-way dual language education; monolingual English-oriented schooling has resulted in inadequate academic and linguistic development, low levels of native language proficiency and inadequate literacy skills in both languages. In contrast, dual language education offers a sound alternative, increasing culturally and linguistically diverse students' academic and linguistic development (Soltero, 2004; Thomas \& Collier, 2002).

For nearly half a century, educators have struggled to develop effective models for teaching children who are English language learners (ELLs). Many have viewed non-native English speakers as academically deficient, needing to be "fixed" and have placed ELLs in the "problem student" category. School remediation programs, however, have typically provided students with less access to the standard curriculum, thus magnifying the achievement gap. 
Inequities have been exacerbated as those with fewer resources and less access to mainstream education have fallen further behind their native Englishspeaking peers.

Dual language programs have begun to step in to recalibrate the prism through which native language instruction and its role in closing the achievement gap for ELLs and immigrant children is viewed. The focus is on academic enrichment for all students, enabling teachers to learn to collaborate with parents and communities, and in turn, recognizing students' and their families' linguistic and cultural experiences as a resource for learning (Pérez \& Torres-Guzman, 2002; Soltero, 2004).

\section{Science Education for Middle School Educators: Active Learning in Culturally Responsive Contexts}

Within the culturally responsive context of schools like Alicia Chacón, UTEP future teachers experience innovative approaches to teaching/learning in diverse content areas. UTEP's teacher preparation program partners with effective schools like this one, effectively preparing future teachers to develop the skills and knowledge needed to work effectively with all children, including ELLs and recent immigrants in culturally, linguistically diverse communities/schools. Teacher candidates spend 650 hours over two semesters in Professional Development School (PDS) classrooms, and are assigned to field experiences in high-need partner schools, many of which have predominantly Hispanic student populations.

In science and mathematics, the critical need for preparing high quality teachers with solid understanding of learning theory, extensive pedagogical skills and a full range of content knowledge is magnified by national scrutiny in relation to U.S. public schools. Recent international reports, for example, found that U.S. education had a "splintered vision"; standards in science and mathematics education are not only unfocused, but frequently aim at the lowest common denominator (Schmidt et al., 1997). Compared to teachers in 50 other countries, U.S. science teachers are expected to address a wide range of subjects, yet they seldom have the time to teach them in depth. As a result, pupils often take a piecemeal approach to learning content information as the boring memorization of facts that are seemingly irrelevant to their everyday lives. Moreover, the research indicates that the performance of U.S. fourth-graders in both mathematics and science was lower in 2003 than in 1995 relative to the 14 other countries that also participated in these international studies (IEA, 2005).

The focus in UTEP's field-based education program can be defined as an integrated conceptual teaching and learning framework. The curriculum consists of carefully selected and designed activities that engage the learner in multiple processes that take place throughout the project. These processes include acquiring critical knowledge, integrating native language literacy, engaging parents as partners, developing proficiency in problem solving, guiding self-directed learning, and participating in collaborative teams. Interactive, reflective approaches give students the ability to think critically by working through problems logically and making connections to the real world. 
As future teachers engage in learning through experience in the field, these classes provide rich opportunities for developing new understandings about pedagogical content knowledge (Magnusson et al., 1999) that will help to shape their professional work as highly competent and highly qualified educators.

\section{A Science Education Model: "Ciencia en Nuestras Casas"}

Future science teachers need practical experiences in which they can interact directly with culturally and linguistically diverse students and their families in culturally responsive contexts, such as a school culture that validates native language and parental involvement. The 'Science in Our Homes - Ciencia en Nuestras Casas' Project, implemented in the College of Education (COE) at the University of Texas at El Paso (UTEP), illustrates an effective response to this need in the field of teacher education. The project involved future teachers in early childhood (EC-4) and middle grades (4-8) certification programs, who participated in a series of community service learning workshops designed to increase students' and parents' knowledge of basic science concepts.

In the fall of 2005, UTEP teacher candidates enrolled in science methods classes for early childhood (ECED 4311) and middle grades (MSED 4311) led a series of community based workshops at the Alicia Chacón International School, designed to engage parents and students in learning science in an interactive dual language context. The teacher education courses explored the methods and materials needed for teaching science and included hands-on inquiry-based demonstrations and explorations. In these classes, the UTEP students designed and implemented science activities in two languages that engaged predominantly Hispanic family members as partners in the teacher and learning processes. The teacher interns were prepared to facilitate miniworkshops introducing science content in both English and Spanish to effectively interact with the community participants. These future educators planned and implemented a series of hands-on science experiences that children and their parents could do in their own homes, using common and readily available household products. The workshop format also enabled the future teachers to develop skills of inquiry within the activities. The experience indicated that they had learned how to carefully observe the outcomes of these lessons, develop new strategies for working with culturally/linguistically diverse parents, students, staff and other community member participants, and document new understandings generated from these efforts.

The future teachers from UTEP planned the family science night activities in direct interaction with parents and families. Over the course of the semester, the future teachers prepared and facilitated three separate workshops which consisted of hands-on science activities. The presentations and materials were prepared in English and Spanish, and geared to the respective developmental levels of students in Grades K-2 (Session 1), 3-6 (Session 2), and 7-8 (Session 3). In facilitating the activities within the community, the educational strategies employed by the future teachers were planned and developed from a constructivist framework, enabling learners to experience content in contexts that help to address misconceptions and to develop proper 
conceptual connections (Wu et al., 2005). This instructional strategy allowed students the time they needed to explore, understand and reflect upon experiences, which lead to synthesis and understanding at a deep level.

The future teachers engaged in interactive dialogue and utilized questioning strategies with parents in order to gain a deeper understanding about their perspectives on partnering with teachers. In these dialogues (conducted in both Spanish and English), parents shared valuable insights. Excerpts from these interviews follow here:

¿Que tan importante cree Ud. que es el apoyar a su hijo con las materias escolares?* [How important do you feel it is to help your child with homework?]

Es importante apoyar a mi hija con las materias escolares para que ella así pueda comprender aún más las cosas que está hacienda o leyendo... * [It is important to help my daughter with her homework so that she can understand the things that she is doing or reading even better...]

¿Cual es la barrera más grande que dificulta su participación más frecuente en la escuela de su hijo?* [Which is the biggest obstacle that makes it hard for you to participate regularly in school with your child?]

Estoy trabajando tiempo completo y estudiando en clases de inglés a la vez.....* [I am working full time and going to school to learn English at the same time....]

A primary goal of the project was to help future teachers to think critically and creatively about the benefits of including parents as partners in educational programs. The project also examined the multiple roles that culturally and linguistically diverse families play as partners with teachers in enhancing children's educational achievement (Delgado-Gaitan, 2004; Lareau, 2000; Munter, 2004; Pérez-Carreon, Drake, \& Calabrese, 2005). In the context of science education, this effort allowed parents and future teachers to model approaches designed to nurture the children's inherent curiosity and to develop a foundation for scientific literacy within the community. By making practical connections between schools and communities within science lessons, there are unique opportunities to make correlations between scientific concepts and real world situations and events (see Robertson, 2005 for further detail). The project helped the future teachers to understand that partnerships with parents are essential to becoming effective educators, not only in science education, but for all content teaching and learning.

\section{Preliminary Outcomes}

The data that follow below were collected from students $(n=31)$ enrolled in ECED 4311 and MSED 4311 during the fall 2005 semester. 84\% of the participating students self-identified as Hispanic-American, $6 \%$ of the students described themselves as White, $3 \%$ as African-American; the remaining students 
chose not to identify any ethnic category. A vast majority of the students enrolled in these classes planned to enter careers in education - 90\% intended to become teachers, $3 \%$ planned to become school counselors, $3 \%$ wanted to pursue a career in school administration. A majority of the students (55\%) planned to teach in elementary schools; $32 \%$ intended to become middle school teachers, and $13 \%$ were preparing to become special education teachers.

Preliminary results from the project indicate that students' knowledge and understanding of the role of parents/community as partners were enhanced through the hands-on, interactive experiences of the project. Following their participation in this project, students responded to questionnaires to measure their attitudes and skills about this dimension of teaching, and the results provide useful information about the value of learning to work with families and parents in authentic contexts (see Table 1).

Table 1. UTEP Student Attitudes towards Parental Involvement*

$$
\begin{aligned}
& \text { MSED } 4311 \text { \& ECED } \\
& 4311 \text { - Fall } 2005 \\
& \text { 'Yes, very important' }
\end{aligned}
$$

Is it important to have at least one conference with a parent of each one of your students?

Is it important that you provide activities that parents can

$100 \%$ do at home to help students improve their grades?

Is it important that you request information from parents in relation to their child's talents, interests, and needs?

$81 \%$

$58 \%$

Is it important to involve parents as volunteers in the classroom?

Is it important to inform parents when their child does something well or improves?

$$
* n=31
$$

Participant results from this project seem to indicate that these future teachers have gained new knowledge and understanding about the value of partnerships with parents, including those who may not have achieved fluency of the English language. Students responded to questions about the value of planning for ongoing communication to help the teacher learn about each child's background knowledge, and help parents learn about their own roles as teacher and mentor at home. Furthermore, the UTEP students described their own motivation to learn more about interacting with parents as partners (and as volunteers) in the classroom.

\section{Future Teachers' Perspectives: In Our Own Words}

These educational learning experiences, conducted in the bilingual/bicultural context of a multilingual school, provided rich opportunities for praxis, helping college students, professors, and K-12 partners to construct new meanings about education within the context of action and reflection in a highly interactive social situation. The community service learning project Science in Our Homes - Ciencia en Nuestras Casas allowed UTEP students to interact directly with more than 50 parents and community members at each "Parent Night" session. 
The interactive workshop format allowed the teacher candidates to deepen their own instructional knowledge by trying out diverse methods of inquiry in each workshop. In turn, this helped the future teachers to better understand the need to develop and strengthen partnerships with culturally and linguistically diverse parents, students, staff and community members.

In the following section, the voices of future teachers with whom we worked in the Science in Our Homes - Ciencia en Nuestras Casas project will be heard. This method of data presentation gives first priority to the perceptions, ideas and themes that emerged as these project participants described key impacts of the processes of collaborative planning, implementation and evaluation of this project on schools, families and the education of future teachers. The responses of project participants are grouped here around key issues as identified by the future teachers. In reality, these teacher candidates were not all seated at a table speaking about the project at a single time and place. Rather, the co-authors reflected carefully on the qualitative data collected from over more than ten months of action research and grouped selections from the students' voices in a question-answer format to highlight the central themes that emerged from the data.

What were some of the most important elements of the Family Science activities that you planned and implemented?

*Cecilia: One of the things I learned is that in order to be successful in involving parents in education, we have to mold the language of science into something that they can understand .... [I]n this region we have a lot of parents that come from Mexico. A lot of them don't have a degree, or a high school degree. So if we start talking in scientific terms, it's going to be hard to connect with them. One of the things we did was to simplify the language in the book we created**, so parents and their children could do the science at home, and understand why it was happening .... I think language is very important to have good communication with parents. They do understand English, but sometimes they prefer to communicate in their native language. ... Having the dual languages (English and Spanish) opens doors of communication. [**See Appendix A for a sample activity in English from Science in Our Homes Ciencia en Nuestras Casas curricular materials (Robertson, 2005)].

*Ana: It was neat to see all the parents walking around with their children, watching them learn ... I feel that this exemplifies to students, that even as adults their parents are still learning. They get to see that it is okay not to know all the answers all the time, and that it is more important to have the ability to figure out anything they want to know. It is good to provide experiences in which students feel that their learning is important to the community. This type of activity will get them accustomed to want to do this with their children as they grow older. 
*Cindy: The parents were just as involved as the students. Some would ask me questions expecting me to answer them directly, but I would turn the questions around on them just as I would the students. I think they were surprised at this method since they are not accustomed to it. I think they were more surprised to find that they already had the answers to the questions they had just asked me. They were very supportive of this technique. I even noticed one parent using this questioning strategy on her son after he asked me a couple of questions!

*Marc: At the end of the night I was very pleased because I felt I did something for the school community by sharing my knowledge with parents, faculty and students. I also felt comfortable presenting and asking questions to the families once they were at my learning station. I think that every school should include some type of family night, not just a parent conference night. This really creates an inviting environment where everyone is welcomed. I was really pleased to hear that everyone was able to receive a packet of the activities so that they can try them out at home and enjoy it together. All and all this was a great experience and as a future teacher I plan to integrate something similar to this in my classroom where students and parents work together.

\section{How do you now see the roles of parents in science education?}

*Francisco: I really enjoyed attending and participating in the event. It was nice to see the school foster education by promoting parental involvement. I had known that parental involvement in education is definitely important but it is rare to see school administrators [and university partners] actually put programs like this together for parents.

*Eliana added: I was really surprised to see how parents and students were so involved in the activities that each learning station provided. The turnout was unbelievable and I really enjoyed seeing students, teachers, and parents come together. The one thing that I enjoyed the most was having the student bring his or her parent to the learning station in such an enthusiastic way. This proved to me that students want their parents to know what they are learning and involve them!

\section{Conclusion}

Science in Our Homes - Ciencia en Nuestras Casas involved teacher educators from the University of Texas at El Paso (UTEP) in a series of community-based workshops designed to increase students' and parents' understandings of basic science concepts. This approach showed future teachers that working directly with ELL students and families in their community and modeling sound pedagogical practices can facilitate learning in border communities. Using science education as a focus, the teacher interns made the teaching and learning opportunities easily accessible by utilizing common household products and by providing activities that families could do at home. The workshop format allowed the future teachers to focus on methods of inquiry within the activities 
and to develop pathways to establishing partnerships with the parents, students, staff and other community members that attended the outreach effort.

Student and community participants provide rich information and insightful reflection on the powerful learning generated through these ongoing partnership activities. These findings enable schools and university personnel to continually grow and develop collaborative, integrated design for high quality teacher preparation in multilingual, multicultural contexts. Innovative partnerships such as the example illustrated here, built on inquiry-based pedagogies in science with a community service learning focus, help to contribute to strengthening the preparation of high quality new teachers at UTEP, while enhancing K-12 learning opportunities throughout the U.S.Mexico border community. Teacher education initiatives with a field-based community service focus provide future teachers, students and parents opportunities to learn from practical, hands-on experiences. In participating in such efforts and facilitating educational activities in the community, future teachers develop new skills in their roles as both active participants and reflective practitioners, helping to rethink the nature of the relationship between parents and teachers in culturally/linguistically diverse contexts.

* Pseudonyms are used to prevent identification of individuals, and use of student interviews/written work is restricted to those individuals and classes from whom we obtained full voluntary written consent.

**Projects like 'Science in Our Homes - Ciencia en Nuestras Casas' have been developed with generous funding from diverse sources (including the Carnegie Foundation's 'Teachers for a New Era Grant' and the U.S. DOE FIPSE-funded 'Parent Teacher Educator Connections'). 


\title{
Appendix A - Sample Activity
}

\author{
Blast Off \\ Grades 6-8 Time: 30 min
}

TEKS : Science Concepts. The student knows there is a relationship between force and motion.

We have been flying in space for more than 40 years. A lot of things have changed. Flying on the Shuttle is a treat compared to earlier spaceflights. Forty years ago, people would not have thought Americans and Russians would live together in space. Now, they are! Space probes have visited every planet except Pluto. And a mission there is being planned.

One thing has changed very little. That is the way rockets work. Different fuels have been used. Rocket engines are more high-tech. But, the basic ideas are about the same. NASA is working on a way to change that. What should a new engine do? It needs to be faster. Rockets go the same speed as 40 years ago. A new engine would make space travel faster. It would do other amazing things, too. It could go to Mars faster or get fuel there.

But, have you ever wondered how a space rocket blast off in to space? Or what makes is move in the right direction? In this activity you will be learning about Newton's Third Law of Motion which says:

\section{For every force there is an equal and opposite force}

Things you'll need: 17 feet of string; scissors; plastic straw; tape; yard stick; balloons; marker; paper.

What you do?

1. - Cut a piece of string $15 \mathrm{ft}$ long. Mark the string at every 6 inches. Thread the string through the straw and tie the ends of the string to the back of two different chairs. Push the straw in to one of the far ends of the string.

2. - With the other piece of string (about $2 \mathrm{ft}$ long), mark the string at half inch intervals. This string will be used to measure the circumference of the inflated balloon. 
3. - You or your child can blow-up the balloon, but don't tie it up. Have your child measure the balloon around the widest part of it (circumference), and write down your answer.

4. - While still holding the balloon shut, tape it to the straw and then release the balloon.

5. - Measure the distance that the balloon traveled across the string and right down your results.

6. - Repeat step 3 to 5, blowing up the balloon to different sizes. Remember to record the circumference and the distance the balloon travel every time.

\section{Questions to Think About}

Once your experiment is done ask yourself and your child questions like these to draw up some conclusions.

What is making the balloon move?

What happens to the balloon when you let go of it?

What direction is the air moving?

How will the balloon move farther?

\section{What is going on?}

According to Newton's Third Law, for every action force there is an equal (in size) and opposite (in direction) reaction force. Forces always come in pairs known as "action-reaction force pairs." These actions are two separate forces. A force is a push or a pull upon an object, which results from its interaction with another object. An action force pushes in on direction while a reaction force pushes equally in the opposite direction.

In this activity, the air moves out of the balloon in one direction and the balloon moves in the opposite direction. Forces are equal because the balloon moves according to how much air there is in it to propel it.

\section{Where Does This Happen in Real Life?}

Consider how a fish moves through water. The fish uses its fins to push water backwards and the push causes the fish to move in the opposite direction, 
forward. The size of the force on the water equals the size of the force on the fish.

Imagine a rocket being launched by NASA. A rocket can liftoff from a launch pad only when it expels gas out of its engine. The rocket pushes on the gas, and the gas in turn pushes on the rocket. With rockets, the action is the expelling of gas out of the engine. The reaction is the movement of the rocket in the opposite direction

Extensions: You may repeat the experiment but this time use a stop watch and measure how much time the balloon took to travel. With the data collected you can create a table composed of the time (seconds) the balloon took to move and the distance (inches) it traveled. With this information you can find the speed the balloon was traveling. 


\section{References}

Banks, C. (2005). Families and teachers working together for school improvement. In J. Banks \& C. Banks, (Eds.).Multicultural education: Issues and perspectives, 5th ed. (pp. 421-442). Hoboken, NJ: John Wiley \& Sons.

Calderón, M. \& Minaya-Rowe, L. (2003). Designing and implementing two-way bilingual programs: A step-by-step guide for administrators, teachers, and parents. Thousand Oaks, CA: Corwin Press.

Capps, R., Fix, M., Murray, J., Ost, J., Passel, J., \& Herwantoro, S. (2005). The new demography of America's schools: Immigration and the 'No Child Left Behind'Act. Retrieved 4/15/06 from the Urban Institute Web site: http://www.urban.org/UploadedPDF/311230_new_demography.pdf

Cross, P. (1994). The coming of age of experiential education. NSEE Quarterly, 19(3), 1, $22-24$.

Delgado-Gaitan, C. (2004). Involving Latino families in schools: Raising student achievement through home-school partnerships. Thousand Oaks, CA: Corwin Press.

Dewey, J. (1938). Experience and education. New York: Macmillan Co.

Fry, R. (2003, June 12). Hispanic youth dropping out of U.S. schools: Measuring the challenge. Retrieved July 12, 2003, from the Pew Hispanic Center website. http://www.pewhispanic.org

Hutchings, P. \& Wutzdorff, A. (1988). Experiential learning across the curriculum: Assumptions and principles. In Hutchings \& Wutzdorff (Eds.). Knowing and doing: Learning through experience. (pp. 5 - 19). San Francisco: Jossey-Bass.

Jacoby, B. (1994). Bringing community service into the curriculum. The Chronicle of Higher Education, XI(50), B2.

Kolb, D. (1984). Experiential learning. Englewood Cliffs, NJ: Prentice-Hall, Inc.

Kuh, G. (1993). In their own words: What students learn outside the classroom. American Educational Research Journal, 30(2), 277- 304.

International Association for the Evaluation of Educational Achievement (IEA) (2005). Trends in International Mathematics and Science Study. Retrieved 4/21/06 from the Boston College Web site http://timss.bc.edu/timss2003.html

Lareau, A. (2000). Home advantage. Social class and parental intervention in elementary education. Lanham, MD: Rowman \& Littlefield Publishers, Inc.

Liu, G. (1995). Service-learning: A paradigm change in higher education? NSEE Quarterly, 21(1), 8, 9, 28, 29.

Magnusson, S., Borko, H., \& Krajcik, J. (1999). Nature, sources, and development of pedagogical content knowledge for science teaching. In J. Gess-Newsome \& N. Lederman (Eds.), Science teacher knowledge (pp. 95-132). Dordrecht, Netherlands: Kluwer Academic Press.

Mapp, K. L. (2002). Having their say: Parents describe how and why they are involved in their children's education. Paper presented at the Annual Meeting of the American Educational Research Association, New Orleans, LA.

Munter, J. (2004, Summer). Teacher education in the borderlands: Schools, community, and education for social justice at UTEP. Teacher Education and Practice, 17(3), 279- 298.

Nieto, S. (2002). Language, culture, and teaching: Critical perspectives for a new century. Mahwah, NJ: Lawrence Erlbaum Associates Publishers.

Pérez-Carreon, G., Drake, C. \& Calabrese Barton, A. (2005). The importance of presence: Immigrant parents' school engagement experiences. American Educational Research Journal, 42(3), 465-498. 
Perez, B. \& Torres-Guzman, M. (2002). Learning in two worlds: An integrated Spanish/English biliteracy approach, $3^{\text {rd }}$ ed. Boston: Allyn \& Bacon.

Robertson, W. (Ed.). (2005, Fall). Science in our homes: Ciencia en nuestras casas. (Available from the Department of Teacher Education, University of Texas at El Paso, 500 W. University Ave. El Paso, TX, 79968).

Schmidt, W., McKnight, C., Raizen, S., Jakwerth, P.,Valverde, G., Wolfe, R., Britton, E., Bianchi, L., \& Houang, R. (1997). A splintered vision: An investigation of U.S. science and mathematics education. Dordrecht, The Netherlands: Kluwer Academic Press.

Sheldon, S. \& Epstein, J. (2004) Getting students to school: Using family and community involvement to reduce chronic absenteeism. School Community Journal 4(2), $39-56$.

Soltero, S. (2004). Dual language teaching and learning in two languages. Boston: Pearson Publishing.

Sosa, A. (1990). Making education work for Mexican Americans: Promising community practices. (Digest EDO-RC-90-2). Charleston, WV: ERIC Clearinghouse on Rural Education and Small Schools.

Storch, S. \& Whitehurst, G. (2001). The role of family and home in the literacy development of children from low-income backgrounds. In P. Britto \& J. Brooks-Gunn (Eds.). The role of family literacy environments in promoting young children's emerging literacy skills, $v$ 92. (pp.53 - 72). San Francisco:Jossey-Bass.

Strand, K., Marullo, S., Cutforth, N., Stoecker, R., \& Donohue, P. (2003). Communitybased research and higher education: Principles and practices. San Francisco: Jossey-Bass.

Teitel, L. (2003). The professional development schools handbook. Thousand Oaks, CA: Corwin Press.

Thomas, W., \& Collier, V. (2002). A national study of school effectiveness for language minority students' long-term academic achievement. Santa Cruz, CA and Washington, DC: Center for Research on Education, Diversity \& Excellence. Available: http://www.crede.ucsc.edu/research/llaa/1.1_final.html

Turner-Vorbeck, T. (2005, Winter). Expanding multicultural education to include family diversity. Multicultural Education (13)2, 6-10.

UTEP CIERP (2005). CIERP Fact Sheet. The University of Texas at El Paso Center for Institutional Evaluation, Research, and Planning, El Paso, TX. Retrieved January 12, 2005 from http://www.cierp.utep.edu.

Valencia, R. (1997). The evolution of deficit thinking: Educational thought and practice. Washington, DC: Falmer Press.

Van Hook, J. \& Fix, M. (2000). A profile of immigrant students in U.S. schools. In J. Ruiz de Velasco \& M. Fix (Eds.). Overlooked and underserved: Immigrant students in U.S. secondary schools, (pp. 9-33). Washington, DC: The Urban Institute.

Wu, Y. \& Tsai, C. (2005). Development of elementary school students' cognitive structures and information processing strategies under long-term constructivistoriented science instruction. Science Education 89(5), 822-46.

Zlotkowski, E. (1996, January/February). A new voice at the table? Linking servicelearning and the academy. Change, 28(1), 21-27. 